\title{
CARACTERIZAÇÃO DE POLPA DE CAJÁ EM PÓ OBTIDA PELO MÉTODO DE SECAGEM EM LEITO DE JORRO
}

\author{
A. P. R. FERREIRA ${ }^{1}$, S. L.SOUSA ${ }^{1}$, D.M. LIMA ${ }^{2}$, J. M. C. COSTA ${ }^{3}$ \\ ${ }^{1}$ Universidade Federal do Ceará, Mestranda em Ciência e Tecnologia de Alimentos \\ ${ }^{2}$ Universidade Federal do Ceará, Graduando em Engenharia de Alimentos \\ ${ }^{3}$ Universidade Federal do Ceará, Departamento de Tecnologia de Alimentos
}

E-mail para contato: anaufc2009@hotmail.com

\begin{abstract}
RESUMO-O cajá consiste em um fruto tropical bastante apreciado e consumido, principalmente na Região Nordeste, por apresentar qualidade nutricional e valor comercial, no entanto, por ser perecível apresenta altas taxas de perdas pós-colheita. Dessa forma, torna-se necessário a aplicação de processos que possibilitem seu armazenamento e comercialização por período prolongado. A secagem de alimentos utilizando-se o equipamento denominado leito de jorro tem-se mostrado boa alternativa por fornecer produtos de boa qualidade, tornando-se uma alternativa viável para transformação de frutas, gerando produtos em pó que apresentam maior tempo de vida útil. Este trabalho teve por objetivo a aplicação do processo de secagem em leito de jorro para obtenção de polpa de cajá em pó e posterior caracterização do produto mediante análises físicas e físico-químicas. A partir dos resultados, observou-se que após o processo de secagem ocorreu um aumento no conteúdo de sólidos solúveis, redução no teor de umidade e manutenção do $\mathrm{pH}$ baixo, fatores relevantes para melhor conservação dos pós produzidos. O produto também apresentou aumento no parâmetro de cor referente a luminosidade e coloração menos intensa em relação a polpa. Portanto, o processo de secagem em leito de jorro mostrou-se eficiente na obtenção de um produto de qualidade e com maior tempo de vida útil.
\end{abstract}

\section{INTRODUÇÃO}

O Brasil apresenta destaque no cenário mundial como um dos maiores produtores de frutas com grande potencialidade de mercado. Segundo Oliveira et al.(2009) várias frutas das regiões Norte, Sul e Nordeste apresentam composição em aroma e compostos funcionais de grande valor, particularmente antioxidantes naturais como carotenóides e ácido ascórbico.

Devido ao fato de que a comercialização dos frutos encontra-se relacionada ao período de sua sazonalidade, torna-se necessário a viabilização de processos que possam fornecer essa matéria-prima fora do período de safra. Uma das técnicas que vem sendo aprimorada nos últimos anos é a secagem, visando transformar a polpa de fruta em forma de pó, permitindo um armazenamento mais prolongado e uma maior estabilidade do produto, permitindo ao 
consumidor o acesso ao produto durante o ano, e não apenas no período de safra (Anselmo et al., 2006).

A secagem de pastas e suspensões em leito de jorro tem se mostrado uma alternativa à secagem em spray dryer, fornecendo produtos de alta qualidade e baixo custo, segundo citações de diversos autores (Medeiros et al.,2001). Essa técnica apresenta várias particularidades, proporciona excelente grau de mistura e eficiente contato entre o fluido e o material sólido, favorecendo altas taxas de transferência de calor e massa(Souza,2009).

De acordo com Rocha et al.(2008) a secagem utilizando o leito de jorro permite que se obtenha um pó com granulometria fina e uniforme, utilizando tempos de contato curtos durante o processo. No entanto, materiais ricos em açúcares e ácidos de baixo peso molecular, como as polpas de frutas, produzem pós muito higroscópicos, suscetíveis à aglomeração e com problemas de fluidez. Este problema pode ser evitado ou, pelo menos, minimizado com a adição dos adjuvantes de secagem, que são carboidratos de alto peso molecular, como as maltodextrinas que, reduzem a higroscopicidade dos pós e facilitam o processo de secagem (Bhandari e Hartel, 2005).

A indústria de alimentos em pó tem apresentado crescimento devido às vantagens que a utilização e o manejo dos materiais oferecem, principalmente, no que diz respeito ao seu emprego como matéria-prima ou aditivo, à facilidade de conservação em longo prazo e ao baixo custo com transporte e armazenamento (Souza, 2009). Diante do exposto, o presente trabalho teve como objetivo a aplicação do processo de secagem em leito de jorro para obtenção da polpa de cajá em pó e posterior caracterização do produto mediante análises físicas e físico-químicas.

\section{MATERIAIS E MÉTODOS}

\subsection{Matéria-prima}

Para esta pesquisa foram utilizadas polpas de cajá, sem adição de conservantes, obtidas em uma agroindústria localizada na cidade de Fortaleza - CE. As polpas foram estocadas em freezer à temperatura de $-18,0^{\circ} \mathrm{C}$ até o momento de serem utilizadas no experimentos. $\mathrm{O}$ descongelamento foi realizado na embalagem original do produto, em geladeira $\left(5^{\circ} \mathrm{C}\right)$ por um período de 18 horas.

\subsection{Processamento}

Após o processo de descongelamento, elaborou-se uma polpa formulada composta de polpa integral de cajá com adição de $15 \%$ do agente carreador de secagem maltodextrina. Após completa dissolução e homogeneização, o material foi conduzido ao equipamento denominado leito de jorro modelo FBD 3.0 da marca Labmaq, sendo então submetido ao processo de secagem, seguindo os seguintes parâmetros: vazão do ar comprimido $\left(1,3 \mathrm{~m}^{3} / \mathrm{min}\right)$, vazão de alimentação $\left(4,5 \mathrm{~mL} / \mathrm{min}\right.$.) e temperatura $\left(82^{\circ} \mathrm{C}\right)$. 


\subsection{Caracterização física e físico-química da polpa integral de cajá e da polpa de cajá em pó}

As análises realizadas na polpa de cajá foram: $\mathrm{pH}$, sólidos solúveis e umidade, segundo metodologia descrita pelo Instituto Adolfo Lutz(2008), além da análise instrumental da cor.

Após a obtenção do produto em pó (polpa de cajá) a caracterização foi realizada a partir das análises descritas anteriormente para a polpa, sendo acrescentadas as seguintes determinações: higroscopicidade e grau de Caking.

A análise de higroscopicidade foi determinada a partir da metodologia descrita por Goula e Adampoulos (2008), a qual consiste em espalhar aproximadamente 1 grama de pó de maneira uniforme sobre uma placa de petri (triplicata) e manter a amostra em uma célula com umidade relativa de ar (UR) de 75\% durante um período de 90 minutos, sendo verificado posteriormente o ganho de umidade do pó.

Após a determinação da análise anterior, as placas contendo as amostras foram levadas à estufa a $102^{\circ} \mathrm{C}$ por período de uma hora, sendo em seguida colocadas em dessecadores para resfriamento. Posteriormente, o pó foi desprendido da placa de petri e transferido para uma peneira com malha de $500 \mu \mathrm{m}$, sendo submetido à agitação em um agitador de peneiras para análise granulométrica, marca Bertel LTDA, por cinco minutos. O pó retido na peneira foi expresso como grau de caking (JAYA e DAS, 2004).

\subsection{Análise colorimétrica}

A determinação instrumental de cor das amostras foi realizada através de um colorímetro Konica Minolta Chroma meter CR-410. O sistema de leitura adotado foi o CIELab (HUNTER, 1975), representado pelos seguintes parâmetros: coordenada L* (luminosidade), coordenada de cromaticidade $\mathrm{a}^{*}$ (-a verde, +a vermelho) e a coordenada de cromaticidade $\mathrm{b}^{*}$ (-b azul, +b amarelo), além do Chroma $\left(\mathrm{C}^{*}\right)$ e ângulo Hue $\left(\mathrm{H} 0^{*}\right)$.

\subsection{Análise estatística}

Os resultados foram submetidos à análise de variância (ANOVA) e a média dos tratamentos obtida ao longo do período de armazenamento foi comparada usando o teste de Tukey ao nível de $5 \%$ de probabilidade, utilizando o programa estatístico "Statistica" (versão 5.5, StatSoft, Inc., Tulsa, USA) (Rodrigues e Iemma, 2005). 


\section{RESULTADOS E DISCUSSÃO}

\subsection{Caracterização da polpa integral de cajá}

Os resultados da caracterização físico-química e determinação instrumental de cor realizada nas amostras de polpa integral encontram-se expressos na tabela 1 .

Tabela 1 - Valores médios da caracterização da polpa integral de cajá

\begin{tabular}{cc}
\hline Análises /parâmetro de cor & Resultados \\
\hline Umidade $(\%)$ & $81,76 \pm 0,16$ \\
pH & $2,86 \pm 0,10$ \\
Sólidos solúveis( ${ }^{\circ}$ Brix $)$ & $10,80 \pm 0,26$ \\
$\mathrm{~L}^{*}$ & $60,75 \pm 0,12$ \\
$\mathrm{a}^{*}$ & $8,17 \pm 0,05$ \\
$\mathrm{~b}^{*}$ & $45,94 \pm 0,76$ \\
$\mathrm{C}^{*}($ croma $)$ & $46,99 \pm 0,19$ \\
H(Hue $)$ & $70,98 \pm 0,03$ \\
\hline
\end{tabular}

A polpa apresentou valor de umidade em torno de $81,76 \%$, valor inferior ao encontrado por Mattietto et al.(2010) ao analisar polpa de frutos provenientes de Belém-Pará, onde obteve $89,42 \%$. De acordo com a literatura essas diferenças são resultantes de fatores relacionados ao cultivo dos frutos (clima, solo, sistema de produção, maturação do fruto, sistema de produção dentre outros) e manuseio (colheita, transporte, armazenamento). Em relação ao pH observa-se que a polpa apresentou valor 2,86 , estando em conformidade com a legislação que estabelece valor mínimo de 2,2 (BRASIL, 2000). O resultado referente ao teor de sólidos solúveis $(10,80$ ${ }^{\circ}$ Brix) também está de acordo com o padrão estabelecido pela legislação que preconiza valor mínimo de $9,0^{\circ}$ Brix.

A cor consiste em um parâmetro importante a ser avaliado porque está entre os fatores que influenciam na aceitação de um produto pelo consumidor. A partir da medida instrumental da cor é possível saber de forma objetiva a coloração apresentada pelo alimento. Levando-se em consideração os valores expostos na tabela 1 , observa-se que a polpa apresentou valores positivos para os parâmetros $\mathrm{a}^{*} \mathrm{e} \mathrm{b}^{*}$, indicando coloração alaranjada, característica do fruto. O valor de Chroma indica que a polpa de cajá apresentou cores mais vívidas e em relação ao ângulo Hue, indicativo de tonalidade, observa-se que a polpa de cajá, com valor de 70,98, apresentou coloração laranja com tonalidade próxima à apresentada pelo fruto in natura.

\subsection{Caracterização física e físico-química da polpa de cajá em pó}

Os resultados da caracterização física e físico-química realizada nas amostras de polpa de cajá em pó encontram-se expressos na tabela 2. 
Tabela 2 - Valores médios da caracterização física e físico-química da polpa de cajá em pó

\begin{tabular}{cccccc}
\hline Amostra & $\begin{array}{c}\text { Umidade } \\
(\%)\end{array}$ & $\mathrm{pH}$ & $\begin{array}{c}\text { Sólidos } \\
\text { solúveis }\left({ }^{\circ} \mathrm{Brix}\right)\end{array}$ & $\begin{array}{c}\text { Higroscopicidade } \\
(\%)\end{array}$ & $\begin{array}{c}\text { Grau de } \\
\text { Caking (\%) }\end{array}$ \\
\hline Polpa em pó & $2,51 \pm 0,02$ & $2,81 \pm 0,02$ & $99,00 \pm 0,00$ & 11,25 & 86,08 \\
\hline
\end{tabular}

Em relação ao produto em pó, observa-se que o teor de umidade foi de 2,51\%, estando em conformidade com a legislação brasileira que estabelece valor máximo de $25 \%$ de umidade para produtos de frutas secos ou desidratados(Brasil,2005). Silva (2005b) em estudo realizado com umbu-cajá em pó obtido em secador por aspersão com adição de $15 \%$ de maltodextrina, apresentou valor de umidade semelhante $(2,34 \%)$ ao encontrado nessa pesquisa. Valor de umidade superior $(7,88 \%)$ foi encontrado por Oliveira et al.(2006) ao avaliarem polpa de pitanga submetida ao processo de secagem em spray-dryer.

$\mathrm{O}$ pH $(2,81)$ do produto (polpa de cajá em pó) indica que não houve alteração significativa após o processo de desidratação. A manutenção do $\mathrm{pH}$ baixo é importante para melhor conservação do produto. Valores equivalentes foram encontrados por outros autores. Silva et al.(2005a) ao realizarem um estudo sobre a estabilidade de umbu-cajá em pó obtido por desidratação em estufa com circulação de ar, sob temperatura de $70^{\circ} \mathrm{C}$, verificaram que as amostras apresentaram valor de $\mathrm{pH}$ médio de 3,06, enquanto Gomes et al.(2002) encontraram valor de pH igual a 3,82 ao avaliarem a polpa em pó de acerola obtida por secagem em leito de jorro. Na caracterização da polpa de cajá em pó apresentada neste estudo, a média de sólidos solúveis foi de $99,0^{\circ}$ Brix, o que pode ser explicado pela concentração dos constituintes devido à remoção de água e adição de maltodextrina. Oliveira (2012) em pesquisa com polpa de cajá liofilizada encontrou valor de $92,67^{\circ}$ Brix. De acordo com Chitarra e Chitarra(2005) o teor de sólidos solúveis (SS) é utilizado como uma medida indireta do teor de açucares presentes no alimento, ocorrendo um aumento à medida que há acúmulo de açucares na fruta.

Em relação à higroscopicidade $(11,25 \%)$ do produto desidratado, observa-se que de acordo com GEA Niro (2003), o pó de polpa de cajá é classificado como ligeiramente higroscópico por apresentar valor superior a $10 \%$ e inferior a $15 \%$. De acordo com Barbosa(2010) partículas com baixo teor de umidade, que é o caso do produto em questão, possuem alta higroscopicidade devido à sua grande capacidade de absorver umidade do ambiente, o que está relacionado com o gradiente de pressão de vapor entre as partículas e o ar ambiente. Jaya e Das(2004) ao analisarem polpa de manga em pó obtida por secagem a vácuo (a partir de várias combinações de maltodextrina, glicerol monoestearato e fosfato tricálcico) relataram valores variando de 8,33 a 10,27\% de higroscopicidade nos pós obtidos. De acordo com os autores a higroscopicidade aumenta quando diminui-se a quantidade de maltodextrina usada. Dessa forma, é possível reduzir a higroscopicidade da polpa de cajá em pó, sendo necessário a aplicação de novos testes com concentrações mais elevadas de maltodextrina para verificação do comportamento higroscópico do produto.

O valor referente ao grau de caking $(86,08 \%)$ indica que o produto é inserido na classificação de Gea Niro(2003) como um pó em que ocorre muita formação de caking, ou seja, as partículas constituintes aglomeram-se com facilidade. Jaya e Das (2004) relataram valores inferiores que apresentaram variação entre 10,24 e 11,5\% referente ao grau de caking das 
amostras de polpa de manga em pó avaliadas, afirmando de acordo com seus resultados que nesse caso, mesmo com aumento da quantidade dos componentes de secagem não haveria diminuição no grau de aglomeração das partículas constituintes dos pós estudados.

\subsection{Análise colorimétrica da polpa de cajá em pó}

Os resultados referentes a determinação instrumental de cor realizada no produto obtido após o processo de secagem (polpa de cajá em pó) estão expressos na Tabela 3.

Tabela 3 - Valores de luminosidade $\left(\mathrm{L}^{*}\right)$ e coordenadas de cromaticidade $\left(\mathrm{a}^{*}\right.$ e $\left.\mathrm{b}^{*}\right)$, cromaticidade $\left(\mathrm{c}^{*}\right)$ e ângulo Hue $(\mathrm{H})$ para polpa de cajá em pó

\begin{tabular}{cccccc}
\hline Amostra & $\mathrm{L}^{*}$ & $\mathrm{a}^{*}$ & $\mathrm{~b}^{*}$ & $\mathrm{C}^{*}(\mathrm{croma})$ & $\mathrm{H}(\mathrm{Hue})$ \\
\hline Polpa em pó & $90,68 \pm 0,25$ & $-0,78 \underline{ \pm 0,05}$ & $30,67 \pm 0,18$ & $30,68 \pm 0,18$ & $91,46 \pm 0,09$ \\
\hline
\end{tabular}

Em relação ao produto em pó, observa-se que o valor de L se aproxima de 100, sendo perceptível o aumento na luminosidade. Oliveira (2012) obteve valor de 58,41 para polpa de cajá liofilizada, verificando que durante o período de armazenamento do produto não houve diferenças significativas no valor de L, afirmando que a maltodextrina contribuiu para evitar o escurecimento da amostra.

Com relação aos parâmetros $a^{*}$ e $b^{*}$, observa-se que houve uma diminuição na intensificação da cor alaranjada da polpa de cajá em pó, o que pode ter ocorrido em virtude da ação do agente carreador de secagem(maltodextrina) e da temperatura utilizada no processo, ambos fatores capazes de atuar promovendo alterações na cor original da amostra. Rocha (2009) em seu trabalho sobre a obtenção de extrato de mirtilo em pó (a partir de atomização e liofilização) relatou que a polpa e o extrato apresentaram maiores valores de a*(2,23 e 0,26), tendendo para o vermelho, enquanto que para a coordenada $b^{*}$ os valores ficaram entre $-0,54 \mathrm{e}$ -1,04, tendendo para o azul. Visualmente a coloração da polpa e do extrato de mirtilo apresentaram tonalidade de cor avermelhada e azulada, respectivamente.

$\mathrm{O}$ valor médio do ângulo $\mathrm{Hue}(\mathrm{H})$ do pó foi inferior ao parâmetro Croma. Estas diferenças podem estar associadas à adição de maltodextrina que possui coloração branca e, desse modo, torna menos intensa a coloração dos pigmentos presentes na fruta. Em relação ao valor de Hue, observa-se que o pó apresentou valor de 91,46, indicando coloração próxima ao amarelo. Rocha (2009) verificou que os valores de Hue obtidos para a polpa e extrato de mirtilo foram de $-0,243-1,24$, indicando que o menor ângulo representa a maior intensidade, faixa de cor entre vermelho e azul representando o roxo.

\section{CONCLUSÃO}

O processo de secagem em leito de jorro juntamente com o agente coadjuvante maltodextrina contribuiu para obtenção de um produto com boas características de forma geral, no entanto, essas características podem ser aperfeiçoadas através da realização de novos testes com variações nos parâmetros de secagem. 


\section{REFERÊNCIAS}

ANSELMO, G.C.S.; CAVALCANTI MATA, M. E. R. M.; ARRUDA, P. C.; SOUSA, M. C. Determinação da higroscopicidade do cajá em pó por meio da secagem por atomização. Revista de Biologia e Ciênc. da Terra, v.6, n.2, p.58-65,2006.

BARBOSA, S. J. Qualidade de suco em pó de mistura de frutas obtido por spray drying.2010. Dissertação (Mestrado) - Pós-Graduação em Produção Vegetal, Universidade Estadual de Montes Claro, Minas Gerais.

BHANDARI, B.R.; HARTEL, R.W. Phase transitions during food powder production a powder stability. In: ONWULATA, C. Encapsulated and powdered foods, p.261-292, 2005.

BRASIL. Ministério da Agricultura e do Abastecimento. Instrução Normativa n. 1, de 07 de janeiro de 2000. Regulamento Técnico geral para Fixação dos Padrões de Identidade e Qualidade para polpa de fruta. Diário Oficial [da] República Federativa do Brasil, Brasília, 10 de janeiro de 2000, Seção 1, p. 54.

BRASIL. Agência Nacional de Vigilância Sanitaria Resolução RDC n²72, 22 de setembro de 2005, que dispõe sobre o Regulamento Técnico para produtos vegetais, produtos de frutas e cogumelos comestíveis, Diário Oficial da República Federativa do Brasil, Brasília,DF,2005.

CHITARRA, M.I.F.; CHITARRA, A.B. Pós-colheita de frutas e hortaliças: fisiologia e manuseio. Lavras: UFLA, 2005.785p.

GEA Niro Research Laboratory. Analyticalvmethods dry milk products. GEA Niro analytical methods 15 a. Soeborg, Denmark,2003.

GOMES, P.M.A.; FIGUEIRÊDO, R.M.F.; QUEIROZ, A.J.M. Caracterização e isotermas de adsorção de umidade de polpa de acerola em pó. Ver. Bras. de Prod.Agroindustriais, v.4, n.2, p.157-165,2002.

HUNTER, R. S. Scales for the measurement of colour difference. New York: John Wiley, p.133-140,1975.

INSTITUTO ADOLFO LUTZ. Normas Analíticas, métodos químicos e físicos para análise de alimentos. 3. ed. São Paulo: Instituto Adolfo Lutz, v. 1, 2008.

JAYA, S.; DAS, H. Effect of maltodextrin, glycerol monostearate and tricalcium phosphate on vacuum dried mango powders properties. J. of Food Engin., v.63, p. 125-134, 2004.

MATTIETTO, R. A.; LOPES, A. S.; MENEZES, H. C. Caracterização física e físico-química dos frutos da cajazeira (Spondias mombin L.) e de suas polpas obtidas por dois tipos de extrator. Braz. J. Food Technol., v. 13, n. 3, p. 156-164, 2010. 
MEDEIROS, M. F. D. ; ALSINA, O. L. S.; ROCHA, S. C.; JERÔNIMO, C. E. M.; MATA, A. L. M. L.; MEDEIROS, U. K. L.; FURTUNATO, A. A. Escoabilidade de leitos de partículas inertes com polpa de frutas tropicais: efeitos na secagem em leito de jorro. Rev. Bras. Eng. Agric. Ambient., v.5, n.3, p. 475-480, 2001.

OLIVEIRA, F. M. N.; FIGUEIREDO, R. M. F.; QUEIROZ, A. J. M. Análise comparativa de polpas de pitanga integral, formulada e em pó. Rev. Bras. de Produtos Agroind., v. 8, p. 25-33,2006.

OLIVEIRA, A.C.; VALENTIM, I. B.; GOULART, M. O. F.; SILVA, C. A.; BECHARA, E. J. H.; TREVISAN, M. T. S. Fontes vegetais naturais de antioxidantes. Quim. Nova, v. 32, n. 3,689-702, 2009.

OLIVEIRA, G.S. Aplicação do processo de liofilização na obtenção de cajá em pó: avaliação das características físicas, físico-químicas e higroscópicas.2012. Dissertação (Mestrado) - Departamento de Tecnologia de Alimentos, Universidade Federal do Ceará, FortalezaCE.

RODRIGUES, M. I.; IEMMA, A. F. Planejamento de experimentos e otimização de processos: uma estratégia seqüencial de planejamentos. (Casa do Pão, Campinas, 2005), pp. 325.

ROCHA, A. P. T.; ALSINA, O. L. S.; SILVA, V. S.; SILVA, F. L. H. Cinética de produção de levedura seca em leito de jorro. Rev. Bras. Eng. Agríc. Ambient., v.12, n.1, p. 81-86. 2008.

ROCHA, F.J.G. Avaliação da cor e da atividade antioxidante da polpa de do extrato de mirtilo(Vacciniummyrtillus) em pó. 2009.93f.Dissertação (Mestrado em Ciência e Tecnologia de Alimentos) - Universidade Federal de Viçosa, Minas Gerais.

RODRIGUES, M. I.; IEMMA, A. F. Planejamento de experimentos e otimização de processos: uma estratégia seqüencial de planejamentos. (Casa do Pão, Campinas, 2005), pp. 325.

SILVA, R.N.G.; FIGUEIRÊDO, R. M. F.; QUEIROZ, A. J. M.; GALDINO, P. O. Armazenamento de umbu-cajá em pó. Rev.Ciência Rural, v.35, n.5, p.1179-1184, 2005a.

SILVA, Y. C. Obtenção de cajá em pó utilizando um secador por atomização: caracterização física, físico-química e sensorial do pó. 2005b. Dissertação (Mestrado em Engenharia Agrícola) - Universidade Federal de Campina Grande, Campina Grande.

SOUZA, J.S. Secagem de misturas de polpa de frutas tropicais em leito de jorro.2009.Tese(Doutorado)-Universidade Federal do Rio Grande do Norte, Natal. 